\title{
Incremental-iterative model for time-variant analysis of SFRC subjected to flexural fatigue
}

\author{
Peter Heek (1) - Mark Alexander Ahrens • \\ Peter Mark
}

Received: 16 February 2016/Accepted: 8 July 2016/Published online: 17 August 2016

(C) RILEM 2016

\begin{abstract}
Fatigue behaviour of plain (PC) and steel fibre reinforced concrete (SFRC) is of growing interest in concrete engineering since structural reliability often depends on the concrete's damage state. The current paper deals with its investigation. Starting from a new and universal SN-approach for PC and SFRC based on stress- and material-dependent ductility and a cycle-dependent strain evolution under centric pulsating loads an isotropic and time-dependent material damage parameter is derived. In the framework of the elasto-plastic damage theory, wherein PC and SFRC are idealized homogeneously on macroscopic level, this damage parameter in conjunction with the established envelope concept enables to compute time-dependent stiffness and strength degradations as well as increasing plastic strains. Additionally, an assessment of the total number of cycles to failure of specimens subjected to multi-staged cyclic loading is permitted by a specific damage accumulation procedure. Decisive parameters like fibre type, length, orientation, dosages
\end{abstract}

P. Heek $(\bowtie) \cdot$ M. A. Ahrens · P. Mark

Institute of Concrete Structures, Ruhr-University

Bochum, Universitätsstraße 150, 44780 Bochum,

Germany

e-mail: peter.heek@rub.de

M. A. Ahrens

e-mail: alexander.ahrens@rub.de

P. Mark

e-mail: peter.mark@rub.de and bond on the axial static and cyclic material response are covered. To compute numbers of cycles to failure, deflections and stress redistributions of members exposed to flexural fatigue, the findings are integrated into a plastic hinge model. This accounts for localization of damage after cracking in a discontinuity region typical for both, PC and SFRC. Cycle- and crack-width-dependent deflections are obtained for valid states of equilibriums between external loads and internal stress resultants. To assess macroscopic cracking a strain criterion serves. In the numerical simulation, time-increments are performed according to Lemaitre's jump-in-cycles procedure. For verification test results from literature are recalculated. Theoretical and experimental data are in good accordance on average proving a comparable fatigue behaviour of PC and SFRC in principle. However, fibre's impact on fatigue life and deformation capacities of concrete is ambivalent, depending on specific material and load characteristics.

Keywords Fatigue $\cdot$ Wöhler-curves $\cdot$ Ductility index $\cdot$ Steel fibre reinforced concrete .

Incremental-iterative model · Damage parameter
Abbreviations
$b_{\mathrm{t}}$
Parameter for split of strains in inelastic and plastic parts
$d_{\mathrm{f}}$ Fibre diameter
$d_{\mathrm{t}}$ 


\section{$e$ \\ $E_{\mathrm{c}}, E_{\mathrm{c}}^{\mathrm{fat}}$ \\ $f_{\mathrm{c} / \mathrm{t}, \mathrm{dyn}}$ \\ $f_{\mathrm{t}}^{\text {fat }}$ \\ $f_{\mathrm{c} / \mathrm{t} \text {,stat }}$ \\ F \\ $G_{\mathrm{f}}$ \\ $l_{\mathrm{f}}, l_{\mathrm{b}}$ \\ $l_{\text {peak }}, l_{\mathrm{h}}$}

$L, h, s$

$n=N / N^{\mathrm{f}}$

$n_{1}, n_{2}$

$N, N^{\mathrm{f}}$

$P, M, W_{\mathrm{ucr}}$

$R=\sigma_{\text {min }}^{\mathrm{f}} / \sigma_{\text {max }}^{\mathrm{f}}$

$S_{\text {stat }}=\sigma_{\text {max }}^{f} / f_{c / t, \text { stat }}$

$S_{\mathrm{dyn}}=\sigma_{\max }^{f} / f_{c / t, d y n}$

$V_{\mathrm{f}}$

$w, w_{\mathrm{cr}, \mathrm{E}}$

$\alpha$

$\alpha_{\mathrm{F}-\mathrm{t}}$

$\beta, \gamma, \lambda, \zeta$

$\Delta \varepsilon_{1,2}$

$\Delta \sigma=\sigma_{\max }^{f}-\sigma_{\min }^{f}$ $\varepsilon^{\mathrm{fo}}, \varepsilon^{\mathrm{f} 1}, \varepsilon^{\mathrm{f} 2}, \varepsilon^{\mathrm{fmax}}$

$\varepsilon_{t}, \varepsilon_{t}^{e l}, \varepsilon_{t}^{p l}, \varepsilon_{t}^{i n}$

$\bar{\varepsilon}_{c}, \bar{\varepsilon}_{t}, \bar{\varepsilon}_{e l}, \bar{\varepsilon}_{w}$

$\varepsilon_{\mathrm{t}, \mathrm{cr}}$

$\eta_{\text {bond }}, \eta_{\text {pullout }}$

$\eta_{\varphi}$
Spacing of loading

Initial and degraded Young's modulus of concrete

Rate dependent compressive

(c) or tensile (t) strength of

concrete

Residual strength of concrete

Static compressive (c) or

tensile (t) strength of concrete

Frequency

Fracture energy

Fibre length, bond length

Fibre pullout length, fibre

length associated with shape

bond

Beam's geometry: Length, height, extent of plastic hinge

Related number of cycles to number of cycles to failure

Phase transitions in cyclic creep curve

Number of cycles, number of cycles to failure

Force, bending and resistance moment

Stress ratio, effective stress ratio

Static stress level

Rate dependent stress level

Fibre volume content

Maximum crack width, reference crack width

Ductility index

Factor considering loading history of waveform

Regression coefficients

Strain increments

Stress amplitude

Time-dependent strains in constant amplitude loading Tensile strains: elastic, plastic and inelastic parts

Mean strains

Tensile strain at initial cracking of concrete Efficiency factors for fibre bond and pullout effects Fibre orientation factor
$\kappa_{\mathrm{I}}, \kappa_{\mathrm{II}}$

$$
\sigma_{\min }^{f}, \sigma_{\max }^{f}
$$

$\dot{\sigma}_{m}^{f}$

$\sigma_{\mathrm{t}}, \sigma_{\mathrm{ct}}, \sigma_{\mathrm{f}}$

$\tau_{\mathrm{b}}$

$\varphi, \theta, \delta$
Efficiency factors for fibre

effect

Minimum and maximum

fatigue stress

Mean stress rate

Concrete stresses

Bond stress

Rotation angles and deflections

\section{Introduction}

Today, steel fibre reinforced concrete (SFRC) is widely used in structural engineering since mechanically anchored fibres are suited to reduce crackwidths and spacings and enhance structural integrity significantly compared to plain concrete (PC). The governing but also interacting parameters on macroscopic level are fibre type, bond, dosage and orientation as well as concrete's composition [1-3]. Usually, SFRC exhibits a strong ductile but softening axial material behaviour after cracking due to progressive fibre pullout in static loading. For specific applications strain hardening behaviour can also be ensured by employing high dosages of well anchored fibres. Those fibres of elaborated shape ensure strong bond behaviour with concrete's matrix and often fail with fibre tears. Nevertheless, Young's modulus and concrete strength are not significantly enhanced compared to $\mathrm{PC}$, neither when subjected to compression nor tension.

In case of cyclic loading, internal degradation mechanisms of PC and SFRC are similar and can be compared to the ones in monotonic loading [4-6]. Most results available in literature agree that static load deformation curves form an envelope of deformations at failure observed in constant amplitude tests [7-11]. However, this observation seems to hold true in case of centric rather than eccentric loading only, since e.g. the authors in [12] attribute measured deviations from the envelope to a size-dependent fracture process zone in case of flexural fatigue mainly. Actually, repeated eccentric loading enables a redistribution of stresses on cross-sectional level that leads to more reversals than observed in axial tests [13]. Concurrently, the stress redistribution sets higher 
demands on numerical simulation of concrete's material behaviour being met e.g. by plastic hinge models.

To assess the number of cycles to failure $\left(N^{f}\right)$ in constant amplitude, low and high cyclic loading, SN or so called Wöhler-curves are well established (e.g. $[14,15])$. For these, the stress level $S_{\text {stat }}$, the stress ratio $R$ according to Eq. (1) as well as the frequency $F$ and the waveform of the load history are considered to be the governing parameters of fatigue life.

$S_{\text {stat }}=\sigma_{\max }^{f} / \mathrm{f}_{\mathrm{c} / \mathrm{t} \text {,stat }} \quad$ and $R=\sigma_{\min }^{f} / \sigma_{\max }^{f}$

Consensus is a greater number of cycles endurable decreasing $S_{\text {stat }}$ or increasing $R$ or $F$, respectively (e.g. $[16,17])$. In comparison, alternating stresses, also called stress reversals $(R<0)$, and rectangular waveforms cause failure after lower numbers of cycles than pulsating stresses $(R>0)$ or sinusoidal and triangular waveforms [18]. However, an influence of the loading type (uni- or multiaxial, centric or eccentric) on the fatigue life obtained from $\mathrm{SN}$-curves can nearly be eliminated relating the maximum fatigue strength $\sigma_{\text {max }}^{f}$ to the corresponding static one $f_{\mathrm{c} / \mathrm{t}}$. Accordingly, in case of flexural fatigue, the stress-level $S_{\text {stat }}$ is calculated from the ratio of maximum flexural stress and the flexural tensile strength of concrete. Likewise centrically induced compressive (subscript c) or tensile (subscript $t$ ) stresses are related to the material's axial strength and thus treated conceptually analogue [19]. Doing so, effects of concrete's composition by means of grading curve, pore volume, water-cement-ratio and moisture conditions are included sufficiently, too [20].

In contrast to these generally accepted governing factors, an impact of fibres on the fatigue behaviour of concrete is discussed controversially among experts. It is reported to depend at least on fibre type and loading conditions, e.g. [5, 21-23]. Anyway, to employ the established SN-curves for PC containing variable amounts of steel fibres as well, modifications become necessary.

In Lee and Barr [24] an overview of recent achievements in research on fatigue behaviour of PC and SFRC in the framework of Brite-EuRam [25] is provided. From this it is concluded that the threephased process of progressive internal structural changes (interpreted as damage) until fatigue failure is similar for PC and SFRC. The increase of strains with cycles runs generally affine to well-known s-shaped creep curves. But, fibres might accelerate or decelerate degradation in certain circumstances which is traced back to a dual impact they might have. On the one hand fibres increase the pore and initial micro-crack densities, on the other hand they are able to bridge micro-cracks and retard their growth $[26,27]$. To accurately capture this dual impact of fibres on the fatigue life of concrete, a performance based parameter shall be identified and considered additional to the loading conditions as usual.

In the remainder the fatigue behaviour of PC and SFRC subjected to centric and eccentric loads is illuminated. For this purpose, equations for the axial and time-invariant material response of concrete are presented. Subsequently, a cycle dependent material damage parameter is derived and verified using experimental data from the literature. The new approach is enhanced, transferred to members subjected to bending and finally verified using flexural fatigue tests from the literature.

\section{Uniaxial fatigue of PC and SFRC}

Starting from a macroscopic description of static and uniaxial material response in tension according to Strack [28] a new $\mathrm{SN}-\alpha$ approach is proposed. To provide clearly arranged equations, the derivations are limited to tension subsequently. However, the procedure can easily be extended to compressive loading conditions using the formulae presented in [29] for instance. The introduced new ductility index $\alpha$ in conjunction with stress level $S_{\text {stat }}$ and ratio $R$ as well as frequency $F$ and waveform $\left(\alpha_{\mathrm{F}-\mathrm{t}}\right)$ are used to derive consistent Wöhlercurves valid for PC and SFRC. Then, s-shaped cyclic creep curves in accordance with the envelope concept are presented taking account for dual fibre effect. In the framework of elasto-plastic damage theory, in which PC and SFRC are assumed to be homogenous materials on macroscopic level, time-dependent degradations of stiffness and strength can be assessed. Additionally, an approach for damage accumulation in case of multistaged centric cyclic loading is proposed.

\subsection{Uniaxial material response in tension}

The phenomenological modelling with respect to [28] superimposes effects of fibre geometry, dosage and 
bond behaviour with effects related to PC matrix and fracture energy. Up to the tensile strength $f_{\mathrm{t}}$ linearelastic material behaviour according to Eq. (2) is assumed.

$\sigma_{t}\left(\varepsilon_{t}\right)=E_{c} \cdot \varepsilon_{t} \quad$ for $\varepsilon_{t} \leq \varepsilon_{t, c r}=f_{t} \cdot E_{c}^{-1}$

Material softening after cracking is captured by a mechanically based stress crack-mouth-opening relation $\sigma_{\mathrm{t}}(w)$. It additively superimposes two stress contingents. The first one is of exponential type and covers the PC matrix contribution with respect to the fracture energy $G_{\mathrm{f}}$.

$\sigma_{t}(w)=\sigma_{c t}(w)+\sigma_{f}(w)=f_{t} \cdot e^{-w \cdot f_{t}} / G_{f}+\sigma_{f}(w)$

A multi-factored approach models the second one (cf. Eq. (4)) employing two efficiency factors $\kappa_{\mathrm{I}}$ and $\kappa_{\text {II }}$ assigned to the steel fibres effect that considers crack-width-dependent pullout and bond conditions. $\kappa_{\mathrm{I}}$ gathers the fibres' stress-state with respect to length $l_{\mathrm{f}}$, diameter $d_{\mathrm{f}}$, dosage $V_{\mathrm{f}}$ and orientation $\eta_{\varphi}$ as well as the mean bond stress $\tau_{\mathrm{b}}$. Since it is dimensionless (stress is related to the concrete's tensile strength) $\kappa_{\mathrm{I}}$ lies between the limits of zero and one, while zero marks PC behaviour. $\kappa_{\text {II }}$ covers shape-bond and degradation effects with increasing crack-width by an associated fibre- $\left(l_{\mathrm{h}}\right)$ and pullout-length $\left(l_{\text {peak }}\right)$. Thereby, a pull-out length of $l_{\text {peak }}=0.3-0.7$ is typical for mechanically anchored steel fibres, while $\kappa_{\text {II }}=1.0$ indicates exclusive frictional but no shape resistance, as with straight fibres [28, 29].

$\sigma_{f}(w)=\kappa_{I} \cdot f_{t} \cdot \eta_{\text {pullout }}(w) \cdot \eta_{\text {bond }}(w)$

with: $\kappa_{I}=V_{f} \cdot \eta_{\phi} \cdot \tau_{b} \cdot l_{f} /\left(d_{f} \cdot f_{t}\right)$

$$
\begin{aligned}
\eta_{\text {pullout }}(w) & =\left(1-2 \cdot w / l_{f}\right)^{2} & & \text { if } \mathrm{w} \leq 0.5 \cdot 1_{\mathrm{f}} \\
& =0 & & \text { if } \mathrm{w}>0.5 \cdot 1_{f} \\
\eta_{\text {bond }}(w) & =\frac{w}{a_{\eta} \cdot w^{2}+b_{\eta} \cdot w+c_{\eta}} & & \text { if } \mathrm{w} \leq 1_{\mathrm{h}} \\
& =\kappa_{I I} & & \text { if } \mathrm{w}>\mathrm{l}_{\mathrm{h}}
\end{aligned}
$$

with:

$$
\left\{\begin{array}{l}
a_{\eta}=\left(1 / \kappa_{I I}-1\right) \cdot l_{h} /\left(l_{h}-l_{\text {peak }}\right)^{2} \\
b_{\eta}=1-2 \cdot a_{\eta} \cdot l_{\text {peak }} \\
c_{\eta}=a_{\eta} \cdot l_{\text {peak }}^{2}
\end{array}\right.
$$

Figure 1 recalls the complex load transfer mechanisms of discrete fibres bridging crack edges. Postcracking tensile forces can be covered as long as the

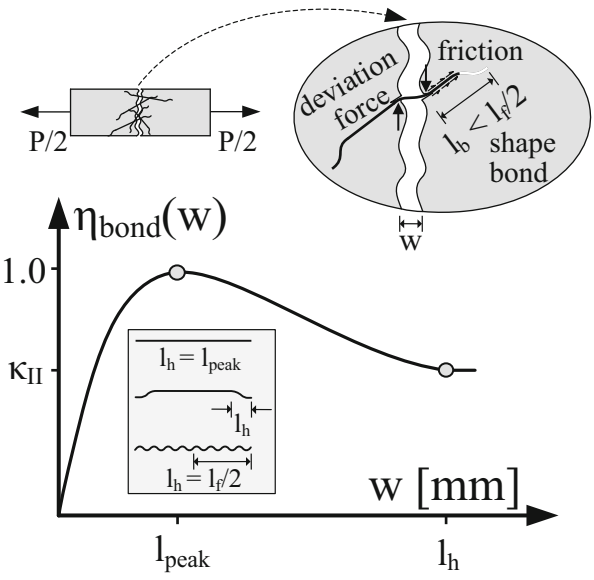

Fig. 1 Complex load transfer at crack edges and the fibre-type dependent course of $\eta_{\text {bond }}$

crack-width is smaller than the total bond length $l_{\mathrm{b}}$, which is equal to half of the fibre's length $l_{\mathrm{f}}$.

Hence, an integrative stress approach is favored here which smears stresses over a crack's length. In Fig. 1 the development of $\eta_{\text {bond }}$ with increasing crack width $w$ according to Eq. (4) is displayed too. It reaches its maximum at 1.0 if the crack width equals $l_{\text {peak }}$ and decreases to $\kappa_{\mathrm{II}}$ at a crack width of $l_{\mathrm{h}}$, which itself depends on the fibre-type.

\subsection{Modified $\mathrm{SN}-\alpha$ approach considering ductility of PC and SFRC}

A stress- and material-dependent ductility index $\alpha$ independent from size effects and the loading rate requires pooling of the static uniaxial stress-strain and stress crack-mouth-opening relations given in Eqs. (2) and (3). Coupled, both form a continuous material model for SFRC covering all intermediate material states up to failure. The conceptual idea behind is to transfer the well-known envelope concept of PC for application with SFRC which says: On an equivalent stress level, the strains at failure $\varepsilon^{\text {fmax }}$ in a constant amplitude fatigue test and the ones induced by static loading according to the stress-strain curve's decreasing branch coincide (c.f. Fig. 2).

Therefore, the stress crack-mouth-opening relation (Eq. 3) based on the "Fictitious Crack Model" by Hillerborg [30] is formally converted into a stressstrain one obeying the "Crack Band Model" by Bazant and Oh [31]. However, and in contrast to [31], the reference length is not associated with the finite 


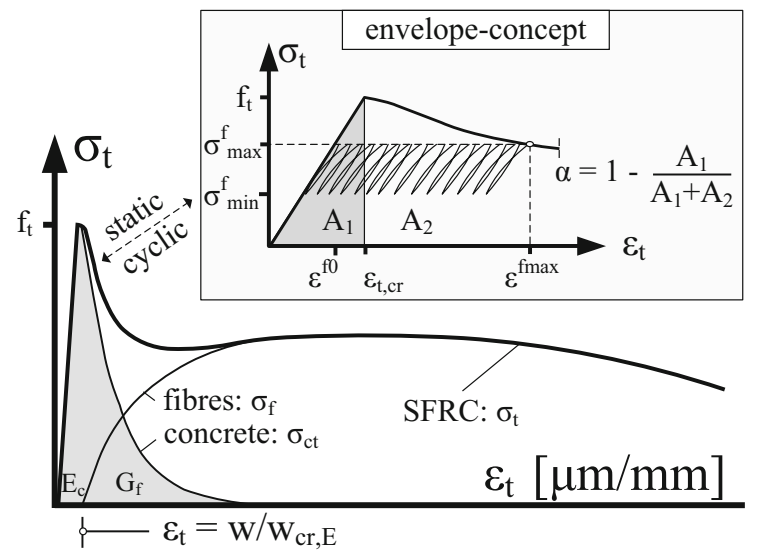

Fig. 2 Static strains constituting an envelope of cyclic strains

size of the fracture process zone as a multiple of the maximum grain diameter but generally set to $w_{\mathrm{cr}, \mathrm{E}}=1.0 \mathrm{~mm}$ instead. Here, the choice of a constant reference length serves to form a unique envelope of stress-strain and stress crack-mouth-opening relation to assess material's ductility. The outcome is not intended to be used for structural analysis directly, as proposed with the original one according to the "Crack Band Model". Figure 2 presents the holistic stress-strain relation derived.

The dimensionless index $\alpha\left(\sigma_{\max }^{f}\right)$ is then defined according to Eq. (5) as the ratio of elastic to total deformation energy integrated from zero to $\varepsilon^{\text {fmax }}$. It implies that (steel fibre reinforced) concrete's deformation energy per unit area at cyclic loading correlates to the integral of the stress-strain relation up to failure strain at monotonic loading. Thus, materials enhanced capacity to absorb energy due to the strengthening mechanism of fibres results in enhanced values $\alpha$. Considering balance of energy, damping effects within hysteretic loops can be neglected since $\alpha$ does not quantify correlations of dissipated energy and fatigue lifetime directly. In fact, it rather serves to classify different concretes based on their deformation energy capacities, interpreted as ductility.

In the framework of the envelope concept, $\varepsilon^{\text {fmax }}$ directly follows from $\sigma_{\text {max }}^{f}$ and thus, the influence of fibre type, bond, dosage and orientation on the static and cyclic behaviour is treated analogously. Per definition the ductility index ranges from $0 \leq \alpha \leq 1.0$, while large values of $\alpha$ mark enhanced ductility features under static and cyclic loading and vice versa.

$$
\begin{gathered}
\alpha\left(\sigma_{\max }^{f}\right)=1-\int_{0}^{\varepsilon_{t, c r}} \sigma_{t} d \varepsilon_{t} / \int_{0}^{\varepsilon^{f \max }} \sigma_{t} d \varepsilon_{t} ; \\
0 \leq \alpha\left(\sigma_{\max }^{f}\right) \leq 1.0
\end{gathered}
$$

A sophisticated derivation and detailed verification is contained in Heek and Mark [32]. The ductility index is used to derive $\mathrm{SN}-\alpha$ curves semi-empirically:

$\log N^{f}=\beta_{0} \cdot\left(1-S_{d y n}\right)+\beta_{1} \cdot R+\beta_{2} \cdot \alpha$

Regression coefficients $\beta_{0}=\sqrt{103}$ and $\beta_{1}=\beta_{2}=$ $0.5 \cdot \pi$ therein have been determined via response surface methodology (RSM), evaluating a database of more than 560 fatigue test results from the literature. As suggested in [33] the effect of load frequency and history of the waveform on the logarithmic number of cycles to failure is generally assigned to the ratedependent concrete strength, which leads to a modified effective stress ratio $S_{\text {dyn }}$ to replace $S_{\text {stat }}$.

$S_{\mathrm{dyn}}=\frac{\sigma_{\max }^{f}}{f_{c / t, \mathrm{dyn}}}=\sigma_{\max }^{f} \cdot\left(f_{c / t, \mathrm{stat}} \cdot\left[\frac{\dot{\sigma}_{m}^{f}}{\sigma_{0}}\right]^{0,0158}\right)^{-1}$

In tension and compression, the rate-dependent strength of PC and SFRC $\left(f_{\mathrm{c} / \mathrm{t}, \mathrm{dyn}}\right)$ in Eq. (7) can be derived using the mean stress rate of cyclic loading.

$$
\begin{gathered}
\dot{\sigma}_{m}^{f}=\left(\sigma_{\max }^{f}-\sigma_{\min }^{f}\right) \cdot F \cdot \alpha_{F-t} ; \\
10^{-6}<\dot{\sigma}_{m}^{f}<10^{5}\left[\mathrm{~N} /\left(\mathrm{mm}^{2} s\right)\right]
\end{gathered}
$$

with $\alpha_{\mathrm{F}-\mathrm{t}}=1.0$ in case of rectangular waveform, $\alpha_{\mathrm{F}-\mathrm{t}}=2.0$ in case of sinusoidal and triangular waveform.

To exclude exponential strength gains at high stress rates, Eq. (8) is limited to the quasi-static domain in dependence on Model Code [1]. Nevertheless, such a restriction is not a limit for most structures of practical relevance. In case of higher stress rates, beyond the scope of this paper, detrimental effects due to appreciable temperature gradients would have to be considered, too [34].

Exemplarily, Fig. 3 presents a subset of experimental fatigue data from the 560 tests already used to fit Eq. (6). Since tensile tests are generally not available yet, the focus is set on compressive and flexural tests of PC and SFRC specimens. In case of flexural fatigue data, inverse analysis using the plastic hinge model presented in Sect. 3.1 has been 
Fig. 3 Verification of $\mathrm{SN}-\alpha$ approach illustrating the influence of $\alpha$ on $N^{\mathrm{f}}$

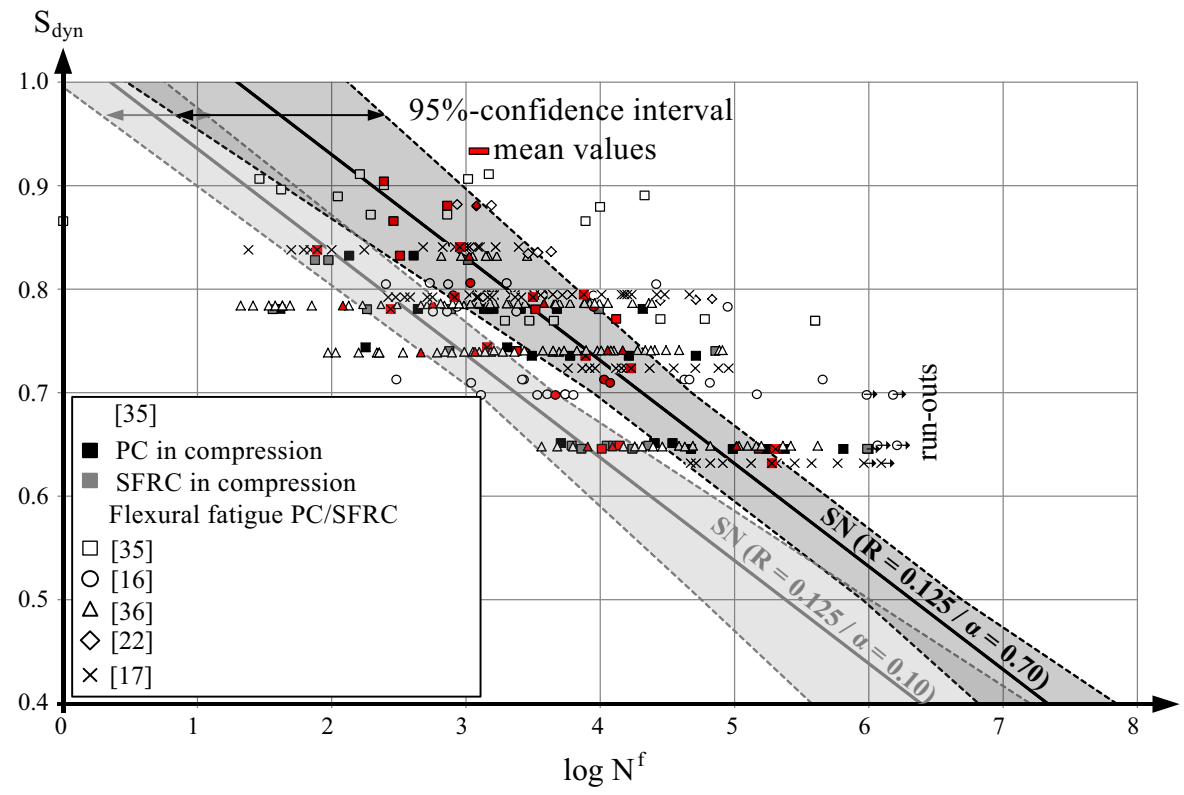

previously performed to gain uniaxial material responses and ductility indices.

Obviously, the experiments are focused on higher load levels of practical relevance associated with $0.65<S_{\text {dyn }}<0.95$. By reason of enhanced numbers of data available, fitting and prediction are statistically more appropriate there as indicated by confidence bounds of reduced extend. Due to the inherent scatter in all fatigue data, serial mean values per load level are calculated and indicated in red. They prove a good accordance with the proposed mean trend functions. For comparison, two representative parameter sets are evaluated employing Eq. (6) that differ in $\alpha$ only. A high ductility index is representative for SFRC and a low one for PC by trend. Thereby, the approach yields enhanced numbers of cycles to failure with increasing capacities of material's deformation energy, expressed by $\alpha$. This goes along with further test results in [37], which proof a strong correlation between fatigue life and dissipated energy during constant amplitude centric loading of PC and SFRC. Correspondingly, the authors in [26] also observed that the amount of cumulative energy during cyclic bending tests is noticeably related to the maximum number of cycles.

Obviously, the new $\mathrm{SN}-\alpha$ approach is able to consider dual fibre effect. It distinguishes between fibres being helpful, since they bridge cracks, or not, since they initiate cracking by means of the stress level $S_{\text {dyn }}$. While at high stress levels additional fibres usually do not influence the number of cycles to failure significantly, their crack bridging ability leads to higher lifetimes at lower stress levels. The approach has originally been derived for the range of $R>0$ but can be extended to stress reversals $(R<0)$ as well. Up to now, it has been verified for normal strength (fibre reinforced) concrete with softening material response after cracking in the range of $-0.3 \leq R \leq 0.5$, $1 \leq F \leq 20 \mathrm{~Hz}$ and $0.55 \leq S_{\mathrm{dyn}} \leq 0.95$ [32].

\subsection{Evolutions of strains and damage}

Progressive damage accumulation in load cycles can be captured by a concrete damage plasticity model. To account for the inelastic material behaviour of concrete, isotropic damaged elasticity and isotropic plasticity concepts are combined herein. Fundamental for the elasto-plastic damage model is an additive split of strains in elastic and plastic portions (subscripts el and pl) according to e.g. [38] and Eq. (9),

$\varepsilon_{\mathrm{t}}=\varepsilon_{t}^{e l}+\varepsilon_{t}^{p l}$

which leads to the stress-strain relation

$\sigma_{\mathrm{t}}=\left(1-\mathrm{d}_{\mathrm{t}}\right) \cdot \mathrm{E}_{\mathrm{c}} \cdot \varepsilon_{t}^{e l}=\mathrm{E}_{c}^{f a t} \cdot\left(\varepsilon_{\mathrm{t}}-\varepsilon_{t}^{p l}\right)$

wherein $d_{\mathrm{t}}$ denotes a scalar damage parameter in its common limits of 0 and 1 . Employing $d_{t}$, damaging effects of concrete cracking are modelled by a reduced 
Young's modulus $E_{\mathrm{c}}^{\mathrm{fat}}$. Assuming a constant ratio $b_{\mathrm{t}}$ of plastic to inelastic strains the damage parameter has been found according to Eq. (11), time-invariant at first.

$d_{t}=1-\frac{\sigma_{t} \cdot E_{c}^{-1}}{\varepsilon_{t}^{i n} \cdot\left(1-b_{t}\right)+\sigma_{t} \cdot E_{c}^{-1}}$

Agreeing to results of (compliance) tests reported in the literature, e.g. [12] a constant and time-invariant value of $b_{\mathrm{t}}=0.50$ is convenient in numerical simulations for both materials, PC and SFRC. Physically interpreted, half of the inelastic strains remain plastic. By contrast, Mark [39] recommends $b_{\mathrm{c}}=0.70$ for PC in compression.

To elaborate the damage parameter to a cycle dependency, the evolution of strains in hysteretic loops is analyzed next. As reported in [18] and [24] for instance, constant amplitude loading causes a threestaged evolution of strains in case of PC and SFRC similar to creep curves. The first part of retarded crack growth involves the weak regions in the concrete matrix, e.g. due to initial shrinkage cracks, and is termed flaw initiation. The second stage is characterized by inherent flaws progressively growing up to a critical size and exhibits accelerated crack growth. For this stage, several authors like in [7, 8] provide evidence for a strong correlation between the rate of crack-growth and the number of cycles to failure. Consequently, the same parameters have to be decisive to describe the evolution of strains that influence fatigue life. Finally, the third stage ends with rupture of the specimen due to accumulations and conjunctions of micro- to macro-cracks and a formation of fracture surfaces. To describe the three-staged cycledependent evolution of strains for both, PC and SFRC, a composite creep function is derived subsequently, incorporating $S_{\mathrm{dyn}}, R$ and $\alpha$ [cf. Eq. (6)].

$\varepsilon_{c / t}(n)=J_{1}(n)+J_{2}(n)+J_{3}(n), \varepsilon^{\mathrm{f} 0} \leq \varepsilon_{\mathrm{c} / \mathrm{t}} \leq \varepsilon^{\mathrm{fmax}}$

$$
\begin{aligned}
& J_{1}(n)=\left(\varepsilon^{f 1}-\varepsilon^{f 0}-\frac{e^{f 2}-\varepsilon^{f 1}}{n_{2}-n_{1}} \cdot n_{1}\right) \cdot\left(1-e^{\frac{n}{n_{1}} \cdot \ln (1 / 100)}\right) \\
& J_{2}(n)=\frac{\varepsilon^{f 2}-\varepsilon^{f 1}}{n_{2}-n_{1}} \cdot n+\varepsilon^{f 0} \\
& J_{3}(n)=c \cdot n^{\frac{\ln \left(f^{0} /(100 \cdot c)\right)}{\ln \left(n_{2}\right)}}
\end{aligned}
$$

with

$c=\varepsilon^{f \max }-\left[\frac{\varepsilon^{f 2}-\varepsilon^{f 1}}{n_{2}-n_{1}}\left(1-n_{1}\right)+\varepsilon^{f 1}\right]$

and

$$
\begin{aligned}
\varepsilon^{f 1}=\varepsilon^{f 0}+\Delta \varepsilon_{1} \cdot\left(\varepsilon^{f \max }-\varepsilon^{f 0}\right) \\
\varepsilon^{f 2}=\varepsilon^{f 0}+\Delta \varepsilon_{2} \cdot\left(\varepsilon^{f \max }-\varepsilon^{f 0}\right) \\
\begin{aligned}
\Delta \varepsilon_{1 / 2}\left(S_{d y n}, R, \alpha\right)= & \beta \cdot S_{d y n}^{3}+\gamma \cdot S_{d y n}^{2}+\lambda+0,075 \cdot \varsigma \\
& \cdot\left[1-(1 / 15)^{0,5 \cdot(R+\alpha)}\right]+0,45 \varsigma
\end{aligned}
\end{aligned}
$$

The creep function $\varepsilon_{\mathrm{c} / \mathrm{t}}(n)$ in Eq. (12) is formulated free of dimensions in the timescale of related numbers of cycles to failure $0 \leq n=N / N^{\mathrm{f}} \leq 1$. Thus, an impact of specific material characteristics (e.g. strain at failure $\varepsilon^{\text {fmax }}$ ) on the shape of cyclic creep function (especially at phase transitions) could be disregarded with intent to grant a wide field of application. Three individual summands $J_{i}(n)$ are superimposed to trace the strains with time. Analogue, the first phase of retarded crack-growth is described with a rational function followed by a linear one, in line with constant crack-growth, and a final power function indicating accelerated crack-growth up to failure. At the intermediate but load-type dependent points of transition, indicated with $n_{1}$ and $n_{2}$, the strain increments $\Delta \varepsilon_{1}$ and $\Delta \varepsilon_{2}$ with respect to the initial strains $\varepsilon^{\mathrm{fo}}$ induced by the maximum fatigue stress $\sigma_{\max }^{f}$ (cf. Fig. 2) fix the strain evolution curve. The type of the strain increment's function results from regression analysis of experimental data from the literature (cf. Fig. 4). Thereby, a cubic relation of $\Delta \varepsilon_{\mathrm{i}}$ and $S_{\mathrm{dyn}}$ is postulated to ensure an s-shaped creep function in either case. The best fit coefficients $(\beta, \gamma, \lambda, \zeta)$ are contained in Table 1.

In Fig. 4 calculated and documented strains from uniaxial fatigue tests performed with PC and SFRC in compression and tension are compared supporting the accuracy of the developed approach. Obviously, all stages of de- and acceleration of strains are reflected accurately.

The cycle-dependent material damage parameter $d_{\mathrm{t}}(n)$ can now be expressed analogue to Eq. (11) with respect to time-variant strains $\varepsilon_{\mathrm{c} / \mathrm{t}}(n)$ by substituting $\sigma_{\mathrm{t}}$ by $\sigma_{\max }^{f}$. Of course, physically, $d_{\mathrm{t}}(n)$ must be of monotonically increasing type. 


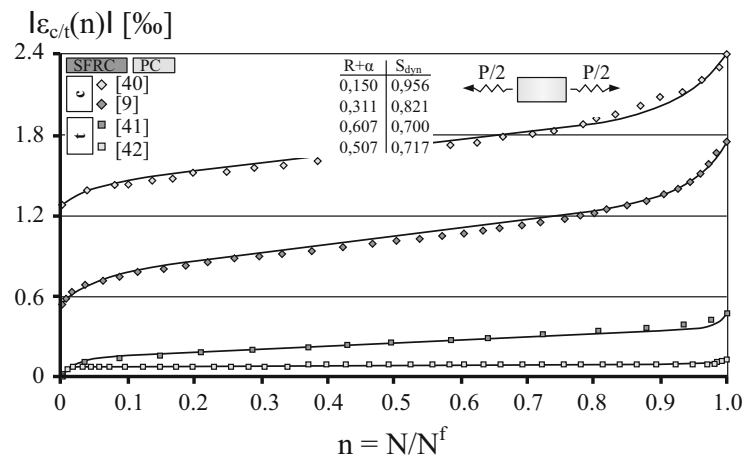

Fig. 4 Evolution of strains over the related numbers of cycles to failure: comparison of measured and computed strains

Table 1 Regression coefficients to gather cyclic strain evolution in tension and compression

\begin{tabular}{lccccc}
\hline & \multicolumn{2}{c}{ Compression } & & \multicolumn{2}{l}{ Tension } \\
\cline { 2 - 3 } \cline { 5 - 6 } & \multicolumn{1}{c}{$\Delta \varepsilon_{1}$} & $\Delta \varepsilon_{2}$ & & $\Delta \varepsilon_{1}$ & $\Delta \varepsilon_{2}$ \\
\hline$\beta$ & -0.064 & -0.028 & & -0.036 & 0.0015 \\
$\gamma$ & -0.031 & -0.122 & & -0.034 & -0.182 \\
$\lambda$ & 0.195 & 0.400 & & 0.200 & 0.440 \\
$\zeta$ & 0.270 & 0.580 & & 0.330 & 0.710 \\
$n_{1}$ & 0.20 & & & 0.10 & \\
$n_{2}$ & 0.80 & & & 0.80 & \\
\hline
\end{tabular}

$$
\begin{aligned}
d_{t}(n) & =1-\frac{\sigma_{\max }^{f} \cdot E_{c}^{-1}}{\varepsilon_{c / t}(n)-b_{t} \cdot\left(\varepsilon_{c / t}(n)-\sigma_{\max }^{f} \cdot E_{c}^{-1}\right)} \\
& =1-\frac{E_{c}^{f a t}}{E_{c}}
\end{aligned}
$$

with $\dot{d}_{t}(n)=\frac{\partial d_{t}(n)}{\partial n} \geq 0$ and $0 \leq d_{t}(n) \leq 1.0$

\subsection{Damage accumulation in variable amplitude loading}

To consider multi-staged loading with variable stress amplitudes, continuity of the damage parameter $d_{\mathrm{t}}(n)$ is postulated similar to the recommendation in [43] and the experimental verification in [44].

Figure 5 exemplarily illustrates the damage progress related to two successive constant amplitude stress levels $S_{i}$, while $S_{1}>S_{2}$. Separately analysed, $S_{1}$ would cause a damage level at failure $d_{\mathrm{t}, 1}\left(S_{1}\right)$ according to Eq. (13) which is lower than $d_{\mathrm{t}, 2}\left(\mathrm{~S}_{2}\right)$. Here, in a two staged procedure, unloading is assumed after $N_{1}$

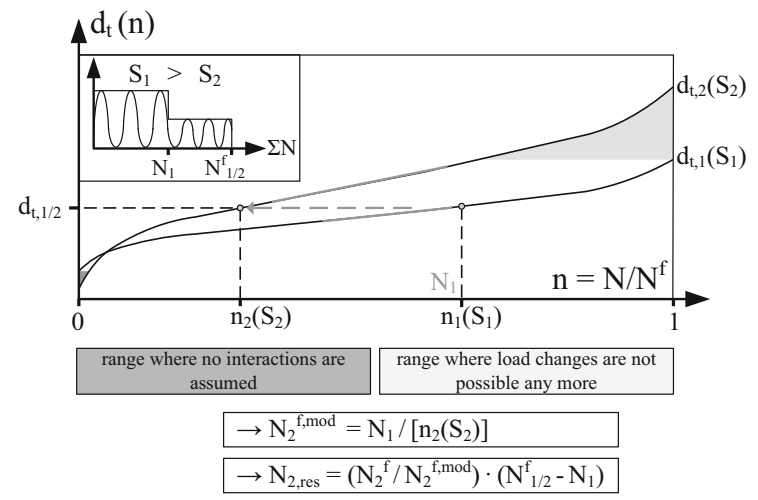

Fig. 5 Continuity of damage during multi-staged axial cyclic loading

load cycles $\left(n_{1}\left(S_{1}\right)\right)$ while the damage level remains fixed $d_{\mathrm{t}, 1}\left(n_{1}\right)=d_{\mathrm{t}, 2}\left(n_{1}\right)=d_{\mathrm{t}, 1 / 2}$ as postulated. According to its original progress curve $d_{\mathrm{t}, 2}\left(n, S_{2}\right)$ the damage level $d_{\mathrm{t}, 2}\left(n_{1}\right)$ theoretically corresponds to $n_{2}\left(S_{2}\right)$. Since $N_{1} / N_{2}^{f} \neq n_{2}\left(S_{2}\right)$ the total number of cycles to failure $N_{2}^{f}$ with respect to Eq. (6) has to be modified ( $\left.N_{2}^{f, \text { mod }}\right)$ to ensure $N_{1} / N_{2}^{f \text {,mod }}=n_{2}\left(S_{2}\right)$. Thus, in case of unloading in a two-staged variable amplitude scenario, greater numbers of cycles to failure are obtained compared to the original number of cycles to failure which matches physical expectation. Moreover, subsequent monotonic strength tests of run-outs often exhibit higher residual strength $f_{t}^{\text {fat }}$ than expected from plain monotonic testing which is usually attributed to consolidation of mortar [7, 18]. In the continuous damage accumulation approach proposed in Fig. 5 the small range of $d_{\mathrm{t}, 2}(n)<d_{\mathrm{t}, 1}(n)$ must be excluded. Therein, no interactions in case of multi-staged loadings are postulated, which leads to unmodified numbers of cycles to failure $N_{1}^{f}$ and $N_{2}^{f}$, respectively. Otherwise, increased numbers of cycle to failure $N_{1}^{f}\left(S_{1}\right)$ would result, if load cycles of lower amplitudes $S_{2}$ were applied previously to $S_{1}$.

In Fig. 6 predictions of total numbers of cycles to failure in a two staged loading procedure are compared to experimental data [45] and a best-fit curve presented therein. On the abscissa, numbers of cycles applied on the first stress level are presented, while the ordinate illustrates residual numbers of cycles to failure $\left(N_{2, \text { res }}\right)$ on the second one. Good accordance is shown except the first third of the unloading branch. However, the well-established Palmgren and Miner rule [46, 47] of linear damage accumulation only fits in a very general 


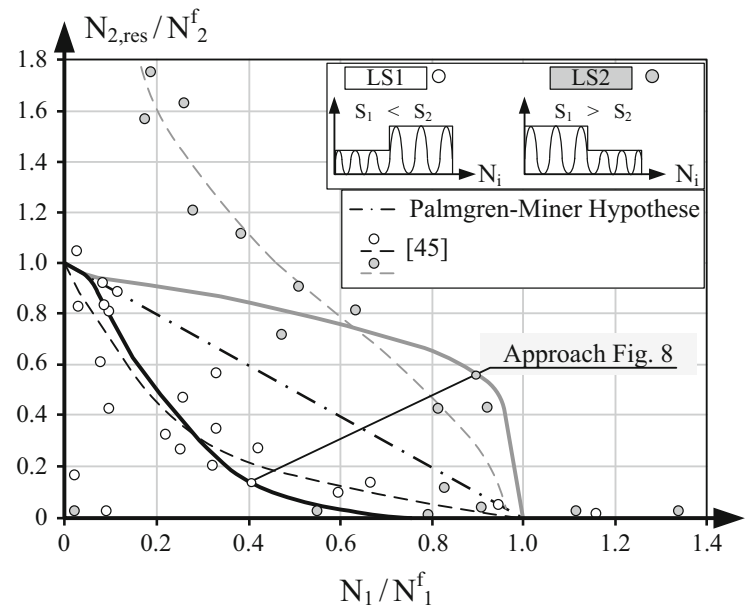

Fig. 6 Total number of cycles to failure in multi-staged loading

way unable to distinguish between loading and unloading as well as sequence effects at all.

\section{Incremental-iterative model for time-variant structural analysis}

To analyse (fibre reinforced) concrete structures subjected to flexural fatigue, the axial and timedependent material model is implemented into a plastic hinge model originally proposed in [28]. It is briefly summarized in its key aspects first and then modified to account for cyclic loading.

\subsection{Plastic hinge model for monotonic static loading}

Based on parametric non-linear finite element analysis, Strack [28] developed a plastic hinge model taking account for distinct localization of damage after cracking, typical for PC and SFRC with softening material response [1-3]. Concrete cracking causes a discontinuity region of limited extent (plastic hinge) characterized by a nonlinear strain distribution over the height $(h)$. The hinge's rotation and the neutral axis are obtained with respect to averaged deflections of the tensile and compressive fibres within the region, respectively (cf. Fig. 7). Equilibrium is checked on cross-sectional level employing lamellae techniques for integration of axial material response. It delivers the crack-width dependent load bearing capacity of the whole structure with respect to the hinge's rotation

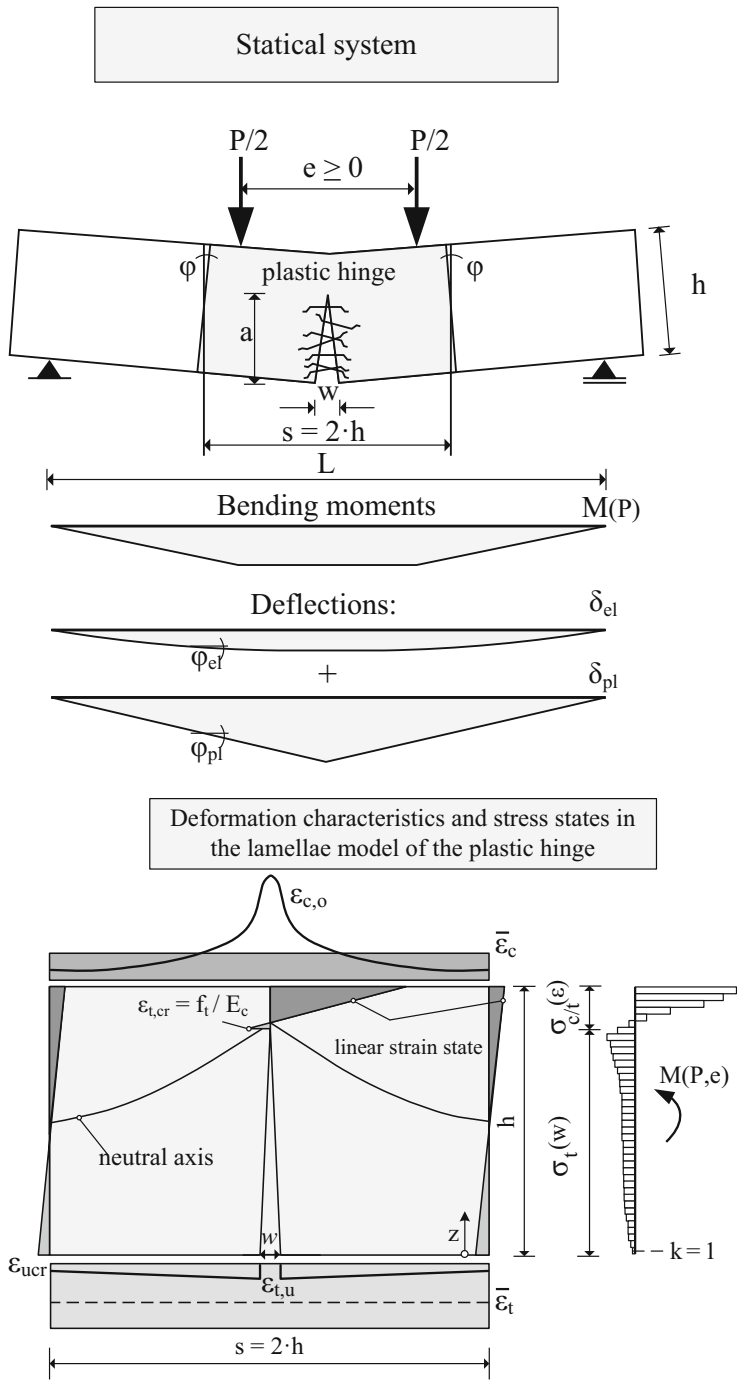

Fig. 7 Plastic hinge model according to [28]

angle $\varphi$. Asides the plastic hinge, sections remain plane, e.g. a linear strain distribution over the crosssections height is maintained according to Bernoulli's theory. Thus, in transition the strains $\varepsilon_{\text {ucr }}$ are directly obtained from linear elasticity theory employing bending $(M)$ and resistance ( $\left.W_{\text {ucr }}\right)$ moments according to Eq. (14), in which the bending moment can be induced by three-point $(e=0)$ or four-point bending $(e>0)$.

$\varepsilon_{u c r}=\frac{M}{W_{u c r} \cdot E_{c}}$

In contrast to this, the averaged tensile strains $\bar{\varepsilon}_{t}$ in Eq. (15) are obtained at the plastic hinge by the sum of 
elastic strains and maximum crack width $w$ smeared over the hinge's width $s=2 \mathrm{~h}$ according to Fig. (7) and [28].

$\bar{\varepsilon}_{t}=\bar{\varepsilon}_{e l}+\bar{\varepsilon}_{w}$

$$
\begin{aligned}
\bar{\varepsilon}_{\mathrm{el}}= & \frac{1}{2 h} \cdot \int_{-h}^{h} \varepsilon_{\mathrm{t}, \mathrm{u}} \mathrm{d} s=\frac{1}{s} \cdot\left(\varepsilon_{\mathrm{ct}, \mathrm{b}, \max } \cdot(h+e / 2)\right. \\
& \left.+\varepsilon_{\mathrm{ucr}} \cdot(h-e / 2)\right) \varepsilon_{\mathrm{ct}, \mathrm{b}, \max }=\frac{M_{\mathrm{max}}}{W_{\mathrm{ucr}} \cdot E_{\mathrm{c}}} \leq \varepsilon_{\mathrm{t}, \mathrm{cr}} \\
= & \frac{f_{t}}{E_{c}} \bar{\varepsilon}_{\mathrm{w}}=\frac{w}{2 h}
\end{aligned}
$$

Thereby, a linear crack opening over the crosssection's height is assumed. Cracking occurs, if the induced strains exceed the cracking strain $\varepsilon_{\mathrm{t}, \mathrm{cr}}$. The mean strain $\bar{\varepsilon}_{e l}$ results from integrating the edge tensile strains $\varepsilon_{\mathrm{t}, \mathrm{u}}$ along the plastic hinge. Accordingly, the nonlinear compressive strains $\varepsilon_{\mathrm{c}, \mathrm{o}}$ summarize to $\bar{\varepsilon}_{c}$. It mainly depends on a crack-width dependent contraction of the compressive zone $\xi(w)$ and iteratively follows from Eq. (16).

$$
\begin{aligned}
\bar{\varepsilon}_{c}= & -\frac{1}{2 h} \cdot \int_{-h}^{h}\left|\varepsilon_{c, o}\right| d s=-\left|\varepsilon_{u c r}\right|-\left(\left|\varepsilon_{c, \max }\right|-\left|\varepsilon_{u c r}\right|\right) \\
& \cdot\left(\arctan (1 / \eta) \cdot\left(\eta^{3}+\eta\right)-\eta^{2}\right)
\end{aligned}
$$

with: $\quad\left|\varepsilon_{c, \text { max }}\right|=\left|\varepsilon_{u c r}\right|+\frac{\left|\bar{c}_{c}\right|-\left|\varepsilon_{u c}\right|}{\arctan (1 / \eta) \cdot\left(\eta^{3}+\eta\right)-\eta^{2}} \quad$ and $\eta=2 \xi(w)=\frac{\left|\bar{\varepsilon}_{c}\right|}{\bar{\varepsilon}_{t}}$

Thus, edge-rotations of the plastic hinge define the rotation angle $\theta$ which itself consists of elastic and plastic portions (subscripts el and pl) according to Eq. (17).

$\theta=2 \phi=2 \cdot\left(\bar{\varepsilon}_{t}+\left|\bar{\varepsilon}_{c}\right|\right)=\theta_{e l}+\theta_{p l}$

with: $\theta_{e l}=4 \cdot\left|\bar{\varepsilon}_{e l}\right|$

Likewise, the vertical deflections $\delta$ of the beam result from superposition of elastic and plastic parts in case of equilibrium of outer loads and inner stress resultants. For statically determinate bending members of length $L$ the crack-width dependent plastic deflections can be read from Eq. (18).

$\delta_{p l}=\frac{1}{4} \frac{w \cdot L}{(1-\xi) \cdot h}$

All computations are carried out in a deformation controlled way. Beam's geometry, load pattern and material behaviour by means of the stress-strainrelations as well as one concrete edge strain are provided. Its counterpart on the other side is iteratively computed employing structural equilibrium conditions. From a permissible cross-sectional strain distribution load-size and the beam's deflection are obtained. Step-wise repetition with continuously increased strain finally delivers the entire loaddeflection curve.

\subsection{Modified plastic hinge model for fatigue analysis}

Subsequently, the presented approach is enhanced to simulate cyclic behaviour. For convenience, the belonging algorithm for incremental-iterative fatigue analysis has been implemented in Matlab ${ }^{\circledR}$. In general, the upper equations remain unchanged. However by contrast, computations are now performed load- and time-controlled. Thus, geometry, load-pattern and load-size-the latter one uniquely defined by means of its cyclic parameters $S_{\text {dyn }}\left(S_{\text {stat }}, F, \alpha_{\mathrm{F}-\mathrm{t}}\right)<1.0$ and $R>0$-are initially preset, while mean edge strains at top and bottom of the plastic hinge are computed iteratively. They replace the two unknowns load-size and edge strain of the original approach. Furthermore, it is assumed that damage localization in cyclic loading occurs similar to the monotonic case, as experimental results gained by acoustic emission analysis advice [48].

Corresponding to the number of load-cycles applied, the (degraded) material behaviour is accounted for lamella-wise. To evaluate material's degradation, the load history is incremented using a jump-in-cycles procedure with respect to [49]. At first, in all increments the lamella stresses are assumed equivalent to the ones obtained from the preceding step in equilibrium. These are always related to the degraded strength according to the envelopeconcept to obtain the current stress-level $S_{\text {dyn }}$. Ductility index $\alpha$ and current stress ratio $R$ follow analogue, while the time-invariant stress amplitude $\Delta \sigma=\sigma_{\max }^{f}-\sigma_{\min }^{f}$ causes variable stress ratios $R$ over time, c.f. [50]. Employing Eq. (6) gives theoretical numbers of cycles to failure per lamella that are related to the total number of load cycles being applied. The dimensionless number of cycles to failure $n$ along with the strain state and the degraded stress-strain-relation of the preceding time-step consistently enable to update the damage parameter $d_{t}(n)$ according to 
Eq. (13). Thereby, strains at failure $\varepsilon^{\text {fmax }}$ correspond to the initial value of $\sigma_{\max }^{f}$ at the outermost fibre of the hinge (cf. Fig. 2). A progressively increasing damage parameter in case of stress redistributions is granted by considering the degraded concrete strength to compute $S_{\text {dyn }}$ as outlined above. Both, damage parameter and stress-strain relation are updated lamella-wise. That way, the total stress and strain states of the plastic hinge are iterated meanwhile equilibrium is preserved. If equilibrium cannot be reached anymore, the belonging time-step is associated with fatigue failure. It should be noted that it is utmost important to choose sufficiently small time-increments, since all are sought to initially have constant stresses here. Thus, Pfanner [43] suggests not to keep constant increments at all but to adapt their sizes according to the expected threephase deformation course. Correspondingly, the timeincrements in phases one (flaw initiation) and three (accelerated crack growth) should be relatively small. Figure 8 simplifies the total approach for fatigue analysis by means of a flowchart.

Figure 9 shows the calculated evolution of stresses, damage and ductility index for PC and SFRC over the normalized cross-section's height $(0 \leq z / h \leq 1.0)$ in case of constant amplitude flexural fatigue with time $\left(N / N^{f}\right)$, respectively. While the first row contains information on all intermediate steps but separately for PC and SFRC, the second row contrasts both materials but restricted to initial and final states only. Obviously, cyclic loading causes significant stress redistributions

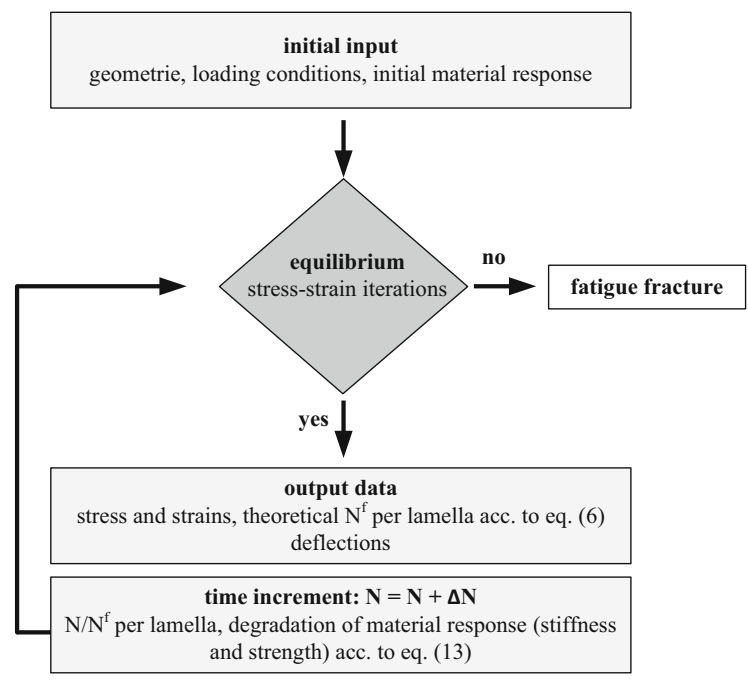

Fig. 8 Computational core of the proposed fatigue model simplified in a flowchart with time resulting in progressive unloading of the outermost lamellae of the plastic hinge. This comes along with a contraction of the compressive zone, as experimentally verified in e.g. [23], and a steadily growing crack process zone (subpictures 9a vs. 9b). The evolution of the crack process zone with time differs for PC and SFRC so that the ductility enhancing impact of fibres due to crack bridging leads to larger numbers of cycles to failure $N_{\text {SFRC }}^{f}>N_{\text {PC }}^{f}$ here. Compared at fracture, the total damage state $d_{\mathrm{t}}$ in case of SFRC is greater than the one for PC (subpicture 9c).

Thereby, only the initial stress-strain relation in tension is assumed to be affected by fibers here. This approach is not restricting when investigating the flexural fatigue response of PC and SFRC, since the degradation process in the compressive zone is generally subordinate to the one in tension due to lower stress levels. It particularly becomes obvious by considering the time dependent evolution of $\alpha$ in compression (subpicture 9d). There, ductility indices are almost identical for concrete with and without steel fibres and approximately constant over time. Small differences are exclusively attributed to the enhanced stress redistribution capacity of SFRC. By contrast, cycle dependent unloading of the outermost lamellae in tension cause progressively increasing ductility indices that significantly differ with fibre's effect.

\section{Verification}

To demonstrate practical relevance and to verify the predicted influence of steel fibres on structural behaviour by means of cyclic crack growth and deflections, experimental data from the literature are recalculated subsequently. The four point standard bending tests in [21] enable to analyze the correlation between deflections at mid-span and fibre dosage. Thereby, four different fibre amounts were investigated in total. As an input for the fatigue model, the uniaxial static response has been derived via inverse analysis of the documented static bending tests using the original plastic hinge model as summarized in Sect. 3.1. Main results are recapitulated in Fig. 10.

Both, fatigue model and test data exhibit threestaged deformation characteristics, in which an increase in fibre content, here primarily expressed by $\kappa_{\mathrm{I}}$, causes an increase of ultimate deflections and 
(a)

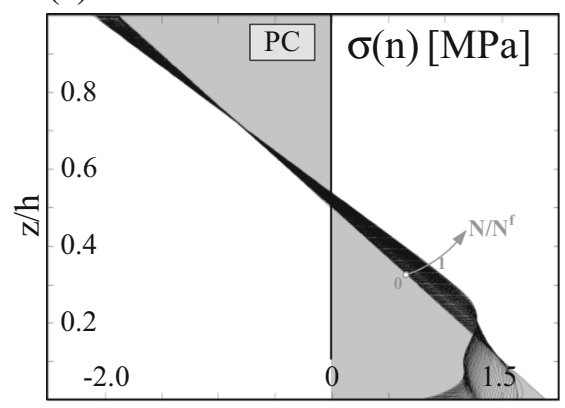

(c)

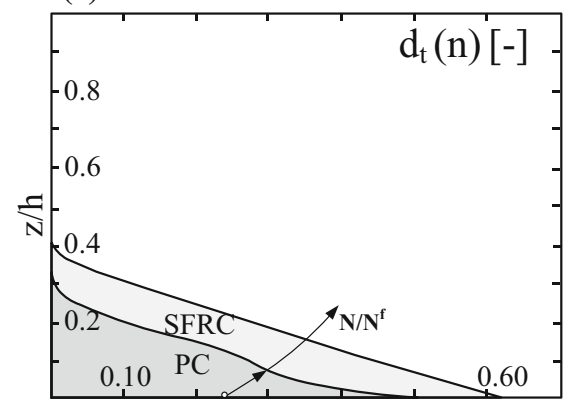

(b)

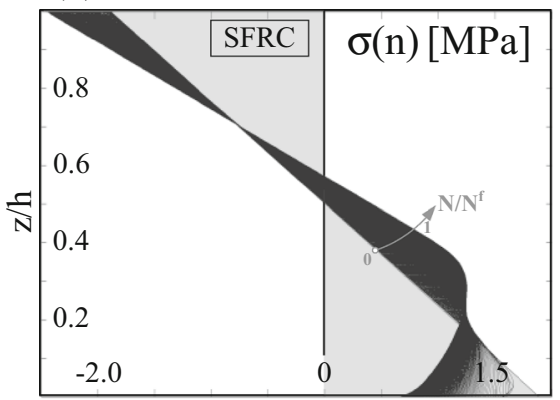

(d)

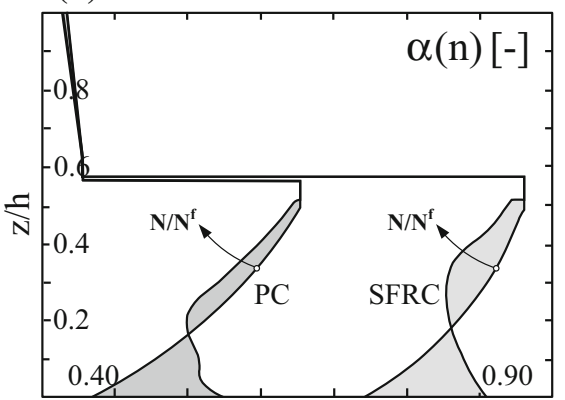

Fig. 9 Cycle-dependent evolution of stresses (subpictures a, b), damage parameter (c) and ductility index (d) for PC and SFRC

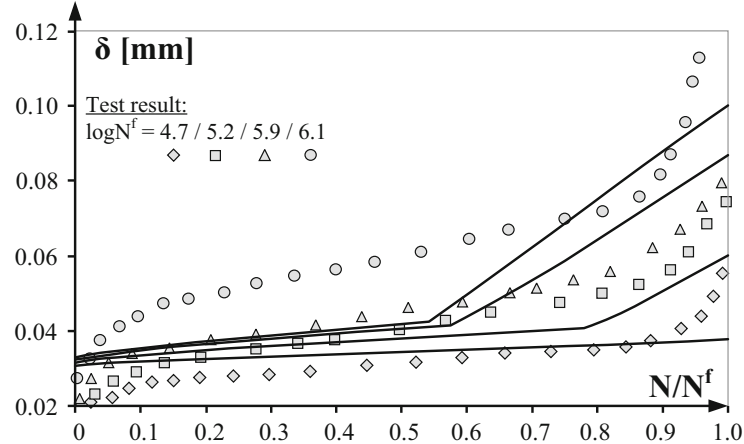

\begin{tabular}{|c|c|}
\hline Geometry & $1 / \mathrm{b} / \mathrm{h} / \mathrm{e}=450 / 150 / 150 / 150[\mathrm{~mm}]$ \\
\hline Cyclic loading & $\mathrm{S}_{\text {stat }}=0.70|\mathrm{R}=0.10| \mathrm{F}=10 \mathrm{~Hz} \mid \alpha_{\mathrm{F}-\mathrm{t}}=2.0$ \\
\hline $\begin{array}{l}\text { Material properties } \\
\text { Vol.-\% SFRC }\end{array}$ & $\begin{array}{l}\mathrm{f}_{\mathrm{t}}=2.70 \mathrm{~N} / \mathrm{mm}^{2} \mid \mathrm{E}_{\mathrm{c}}=25,000 \mathrm{~N} / \mathrm{mm}^{2} \\
\mathrm{l}_{\mathrm{h}}=5.0 \mathrm{~mm} \mid \mathrm{l}_{\text {peak }}=0.30 \mathrm{~mm} \mathrm{|} \mathrm{l}_{\mathrm{f}}=35 \mathrm{~mm} \mathrm{|} \kappa_{\mathrm{II}}=0.20\end{array}$ \\
\hline $0.0(\mathrm{PC}) \diamond$ & $\mathrm{G}_{\mathrm{f}}=90 \quad \mathrm{Nm} / \mathrm{m}^{2} \mid \kappa_{\mathrm{I}}=0.0 \quad I \log \mathrm{N}^{\mathrm{f}}=4,33$ \\
\hline 0.5 & $\mathrm{G}_{\mathrm{f}}=110 \mathrm{Nm} / \mathrm{m}^{2}\left|\kappa_{\mathrm{l}}=0.25\right| \log \mathrm{N}^{\mathrm{f}}=4,82$ \\
\hline 1.0 & $\mathrm{G}_{\mathrm{f}}=110 \mathrm{Nm} / \mathrm{m}^{2}\left|\kappa_{\mathrm{I}}=0.35\right| \log \mathrm{N}^{\mathrm{f}}=5,01$ \\
\hline 1.5 & $\mathrm{G}_{\mathrm{f}}=150 \mathrm{Nm} / \mathrm{m}^{2}\left|\kappa_{\mathrm{I}}=0.42\right| \log \mathrm{N}^{\mathrm{f}}=5,10$ \\
\hline
\end{tabular}

Fig. 10 Recalculation of test-data taken from [21]

number of cycles to failure. Obviously, deflections increase rapidly when a macroscopic crack forms. In case of PC fatigue failure follows quite fast once cracking occurs while fibres bridge cracks and transfer significant stresses. However, macroscopic cracking happens earlier due to the fibres indicating the dual effect they might have. At testing, the logarithmic number of cycles to failure varies for PC and SFRC between $\left[4.7 \leq \log N^{\mathrm{f}} \leq 6.1\right]$, whereas the model yields an interval of $\left[4.3 \leq \log N^{\mathrm{f}} \leq 5.1\right]$. Those differences in $\log N^{\mathrm{f}}$ are quite pronounced but still within the confidence bounds derived for other test data in Fig. 3. However, in both cases increasing the fibre amount yields enhanced fatigue lifes. Deviations concerning the evolution of deflections $\delta$ versus $N / N^{\mathrm{f}}$ between testing and model mainly result from the approximated material parameters used for input. They influence damage parameter $d_{\mathrm{t}}$ according to Eq. (13) and $\log N^{\mathrm{f}}$ according to Eq. (6) lamellae wise. Additionally, the large scatter inherent in all fatigue test data has to be considered. This becomes obvious focusing on the initial strains of the experimental results for instance. Generally, fibre's effect on the monotonic tensile response of SFRC significantly appears after cracking of concrete (c.f. Sect. 2.1) occurs. Thus, strains during the first cycles of the uncracked specimens should theoretically be independent of fibre's dosage. Against this background, the results are in good accordance.

Further analysis of cycle-dependent crack growth can be done referring to test data reported in [12] for instance. The experiments on pre-cracked and notched 
Fig. 11 Recalculation of test-data published in [12]

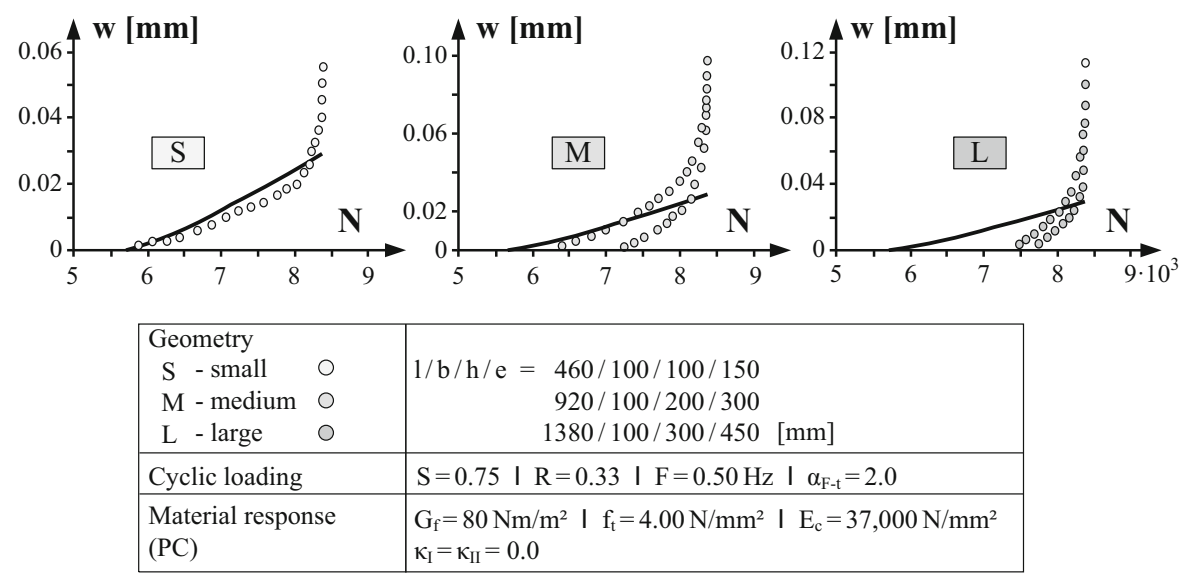

specimens comprise beams of different geometry in order to investigate size effects on flexural fatigue performance of PC and SFRC. During testing, a constant deformation rate was imposed until the load dropped to approximately $95 \%$ of the peak load. Then constant amplitude cyclic loading started. Such a specific load history cannot be adapted by the proposed computational model directly, in which not preloaded specimens can be analysed exclusively. Thus, experimental and theoretical values of $N^{\mathrm{f}}$ cannot be expected comparable. But actually, fatigue dependent crack growth is the main issue here, so the theoretical numbers of cycles to failure are assumed to be equal to the experimental ones (cf. Fig. 11).

Then, experimental and theoretical initiation and growth of fatigue induced cracking are in good accordance on average. Actually, maximum crack width at testing are larger throughout, due to a progressive and irregular reduction of maximum fatigue stresses until the minimum fatigue stress is reached. By contrast, the theoretical model considers just constant amplitude loading for simplification here, which has been the case over a wide range of fatigue life during testing as well. In contrast to experimental data, size effects do not emerge in the recalculation employing the proposed model.

\section{Conclusions}

Experimental results published in the literature on the static and cyclic behaviour of PC and SFRC prove a general comparability on macroscale. Subjected to cyclic loads, three-phased deformation and damage evolution characteristics are typically observed. A significant fibre contribution occurs after cracking of concrete and increases both, post-cracking tensile strength as well as ductility, especially when subjected to tension or bending. With respect to the number of cycles to failure, results at constant amplitude testing highlight a potential contrary impact of fibres. Dependent on stress level, load type and fibre characteristics, increased or decreased numbers of cycles to failure are stated. By means of a newly proposed stress and material-dependent ductility index $\alpha$-that relies on the envelope concept - the dual impact of fibres can sufficiently be covered and integrated into an $S N-\alpha$ approach valid for (fibre reinforced) normal strength concrete with softening material behaviour after cracking. An experimentally proven strong correlation between strain evolution, especially regarding the strain rate in the second phase of fatigue life, and $\log N^{\mathrm{f}}$ advises to characterize both with the same set of parameters. A consistent integration of the derived cyclic creep curves into an elasto-plastic damage model permits to assess stiffness and strength degradations as well as to monitor the evolution of plastic strains over the entire fatigue lifetime.

A close to reality damage accumulation covering multi-staged load sequences gets possible, claiming continuity of the damage progress. It yields higher numbers of cycles to failure in case of unloading and vice versa.

Inclusion of the fatigue damage model in a modified plastic hinge approach enables to deal with flexural fatigue. It has been proven numerically that 
additional steel fibres help to improve to redistribute stresses on cross-sectional level contrasted to PC. Cycle-dependent it comes along with a contradiction of the compressive zone and an increased deformation capacity. Since in PC brittle cracking characterizes macroscopic fatigue failure steel fibres are able to bridge cracks and transfer stresses even after cracking and thus lead to higher numbers of cycles to failure. Obviously, the gains depend on fibre type and stresslevel. In general, cracking starts earlier in case of SFRC than with PC, while at failure, higher damage indices are computed. Thus, the findings confirm the experimentally observed duality of fibers' impact on concrete, which is initiation and bridging of cracks. Which of both dominates in a specific practical case can only be judged considering the interactive contributions of fibre type, orientation and dosage as well as concrete strength and fatigue load by means of $S_{\text {dyn }}\left(S_{\text {stat }}, F, \alpha_{\mathrm{F}-\mathrm{t}}\right)$ carefully. The newly proposed fatigue model contributes in this framework.

\section{References}

1. Fédération Internationale du Béton (2013) fib Model Code for Concrete Structures 2010

2. German Committee for Structural Concrete (DAfStb 2015) Commentary on the DAfStb Guideline "Steel Fibre Reinforced Concrete". DAfStb Heft 614, Berlin

3. RILEM TC 162-TDF (2003) Test and design methods for steel fibre reinforced concrete-background and experiences. In: Schnütgen B, Vandevalle L (ed), Proceedings of 31 RILEM TC-162-TDF workshop, Bochum

4. Mallet G (1991) Fatigue of reinforced concrete, state of the art review/2. Transport \& Road Research Laboratory (TRRL), London

5. Naaman AE, Reinhardt HW (1995) High performance fibre reinforced cement composites 2 (HPFRCC2). In: Proceedings of 2nd international workshop HPFRC, Chapman \& Hill, London

6. Shah SP (1982) Fatigue of concrete structures. Publication SP-75, American Concrete Institute, Detroit

7. Cachim PB, Figueiras JA, Pereira PAA (2002) Fatigue behaviour of fibre reinforced concrete in compression. Cem Concr Compos 24:211-217

8. Cornelissen HAW (1984) Fatigue failure of concrete in tension. Heron 29(4):1-68

9. Otter DE, Naaman AE (1988) Properties of steel fibre reinforced concrete under cyclic loading. ACI Mat J 85(31):254-261

10. Spooner DC, Dougill JW (1975) A quantitative assessment of damage sustained in concrete during compression. Mag Concr Res 27(92):151-160

11. Zhang J, Stang H (1998) Fatigue performance in flexure of fibre reinforced concrete. ACI Mat J 95(1):58-67
12. Plizzari GA, Cangiano S, Cere N (2000) Postpeak behaviour of fibre-reinforced concrete under cyclic tensile loads. ACI Mat J 97(2):182-192

13. Ople FS, Hulsbos CL (1966) Probable fatigue life of plain concrete with stress gradient. ACI J 63(1):1-42

14. Hsu TTC (1981) Fatigue of plain concrete. ACI J 78(4): 292-305

15. Zhang B, Phillips DV, Wu K (1996) Effects of loading frequency and stress reversal on fatigue life of plain concrete. Mag Concr Res 48(177):361-375

16. Mailhot T, Bissonnette B, Saucier F, Pigeon M (2001) Flexural fatigue behaviour of steel fibre reinforced concrete before and after cracking. Mat Struct 34(7):351-359

17. Singh SP, Kaushik SK (2000) Flexural fatigue life distributions and failure probability of steel fibrous concrete. ACI Mat J 97(6):658-667

18. RILEM Committee 36-RDL (1984) Long term random dynamic loading of concrete structures. Mat Struct 17(9): $1-28$

19. Tepfers R (1979) Tensile fatigue strength of plain concrete. ACI J 76(39):919-933

20. Galloway JW, Harding HM, Raithby KD (1979) Effect of moisture changes on flexural and fatigue strength of concrete. TRRL Report LR 864

21. Chenkui H, Guofan Z (1995) Properties of steel fibre reinforced concrete containing larger coarse aggregates. Cem Concr Compos 17:199-206

22. Nanni A (1991) Fatigue behaviour of steel fibre reinforced concrete. Cem Concr Compos 13:239-245

23. Parvez A, Foster SJ (2015) Fatigue behaviour of steel-fibrereinforced concrete beams. J Struc Eng. doi:10.1061/ (ASCE)ST.1943-541X.0001074

24. Lee MK, Barr BIG (2004) An overview of the fatigue behaviour of plain and fibre reinforced concrete. Cem Concr Compos 26:299-305

25. Brite- EuRam BRPR-CT98-0813 (2002) Test and design methods for steel fibre reinforced concrete

26. Germano F, Tiberti G, Plizzari G (2016) Post-peak fatigue performance of steel fibre reinforced concrete under flexure. Mat Struct. doi:10.1617/s11527-015-0783-3

27. Grzybowski M, Meyer Ch (1993) Damage accumulation in concrete with and without fibre reinforcement. ACI Mater J 90(6):594-604

28. Strack M (2007) Modellbildung zum rissbreitenabhängigen Tragverhalten von Stahlfaserbeton unter Biegebeanspruchung. Dissertation, Ruhr-Universität Bochum

29. Gödde L (2012) Numerische Simulation und Bemessung von Flächentragwerken aus Stahlfaserbeton sowie stahlfaserverstärktem Stahl- und Spannbeton. Dissertation, Ruhr-Universität Bochum

30. Hillerborg A (1980) Analysis of fracture by means of the fictitious crack model, particularly for fibre reinforced concrete. Int J Cem Compos 2(4):177-184

31. Bazant ZP, Oh BH (1983) Crack band theory for fracture of concrete. Mat Struc 16(93):155-197

32. Heek P, Mark P (2016) Zur Ermüdung von Beton und Stahlfaserbeton. Beton- und Stahlbetonbau 111(4):221-232

33. Schneider S, Vöcker D, Marx S (2012) Zum Einfluss der Belastungsfrequenz und der Spannungsgeschwindigkeit auf die Ermüdungsfestigkeit von Beton. Beton- und Stahlbetonbau 107(12):836-845 
34. Elsmeier K, Lohaus L (2014) Temperature development of concrete due to fatigue loading. Proceedings of 10th international $\mathrm{PhD}$ symposia in Civil Engineering, Quebec

35. Cachim PB (1999) Experimental and numerical analysis of the behaviour of structural concrete under fatigue loading with applications to concrete pavements. Phd-Thesis, Universidade de Porto.

36. Mohammadi Y, Kaushik SK (2005) Flexural fatigue-life distributions of plain and fibrous concrete at various stress levels. J Mat Civil Eng 17(6):650-658

37. Paskova T, Meyer Ch (1997) Low-cycle fatigue of plain and fibre-reinforced concrete. ACI Mat J 94(4):273-285

38. Meschke G, Lackner R, Mang HA (1998) An anisotropic elastoplastic-damage model for plain concrete. Int J Numer Eng 42:703-727

39. Mark P (2006) Investigations of reinforced concrete girders under biaxial shear using parametric finite element models. In: Meschke $G$ et al (ed) Proceedings of computational modelling of concrete structures, (Euro-C 2006). Taylor \& Francis, pp 739-746

40. Award ME, Hilsdorf HK (1971) Strength and deformation characteristics of plain concrete subjected to high repeated and sustained loads. University of Illinois, Urbana

41. Cornelissen HAW, Timmers G (1981) Fatigue of plain concrete in uniaxial tension and in alternating tension-compression. Report 5-81-7. Delft University of Technology
42. Morris AD, Garrett GG (1981) A comparative study of the static and fatigue behaviour of plain and steel fibre reinforced mortar in compression and direct tension. Int $\mathrm{J}$ Cem Compos Lightweight Concr 3(2):73-91

43. Pfanner D (2002) Zur Degradation von Stahlbetonbauteilen unter Ermüdungsbeanspruchung. Dissertation, RuhrUniversität Bochum

44. Göhlmann J (2009) Zur Schädigungsberechnung an Betonkonstruktionen für Windenergieanlagen unter mehrstufiger und mehraxialer Ermüdungsbeanspruchung. Dissertation, Leibniz Universität Hannover

45. Hilsdorf HK, Kesler CE (1966) Fatigue strength of concrete under varying flexural stresses. ACI J 63:1059-1076

46. Miner MA (1945) Cumulative damage in fatigue. J Appl Mech 67:159-164

47. Palmgren A (1924) Die Lebensdauer von Kugellagern. Z Ver Dtsch Ing 58:339-341

48. Finck F (2002) Acoustic emission analysis of SFRC beams under cyclic bending loads. Otto-Graf-J 13:83-92

49. Lemaitre J (1992) A course on damage mechanics. Springer, Berlin

50. Hordijk DA (1992) Tensile and tensile fatigue behaviour of concrete: experiments, modelling and analyses. Heron 37(1):1-79 